\title{
The analysis of influence factors on plug removal effect in steam injection well of Gaosheng Oilfield
}

\author{
Bencheng $\mathrm{Gao}^{1, \mathrm{a}^{*}}$ \\ ${ }^{1}$ Gaosheng Oil Production Plant in Liaohe Oil-field, Panjin city, Liaoning Province, China, 124125 \\ agaobc@petrochina.com.cn
}

Keywords: Gaosheng Oilfield, plug removal agent, orthogonal test, plug removal effect.

Abstract : In order to improve plug removal effect and optimize operation parameters in steam injection well of Gaosheng Oilfield, the influences of permeability, plugging degree, plug removal agent concentration and injection volume on plug removal effect through orthogonal experimental method in this paper. The result shows that, permeability, the concentration and injected volume of plug removal agent all influence most on plug removal effect. For artificial core of $2000 \times 10^{-3} \mu \mathrm{m}^{2}$ gas permeability, the optimum dosage of plug removal agent is $2.0 \mathrm{PV}$ and the injection concentration is $5 \%$.

\section{Introduction}

Gaosheng Oilfield is a heavy oil reservoir, and is exploited by injecting steam. In the process of steam injection, steam will be injected into the formation, and will make the formation damaged, which will cause the clogging in reservoir pore channels because of the water thermodynamic instability and chemical incompatibility[1]. The process of steam injection and oil production, because of the existence of steam flooding, will lead to the formation of other inorganic scale. Therefore, the chemical plug removal agent has been widely used in Gaosheng Oilfield[2]. According to the characteristics of heavy oil reservoir, and combining with the actual situation of steam injection wells, we select plug removal agent solution correspondingly to restore or increase the permeability of the reservoir near injecting steam well. In this way, injection pressure will be reduced to ensure the steam flooding technology be carried out smoothly. It is necessary to further analyze the influence factors on plug removal effect[3].

\section{Orthogonal experiment design of influence factors on plug removal effect}

This experiment mainly analyzed the influence parameters of permeability, plugging degree, plug removal agent concentration and injection volume on plug removal effect through the core experiment, providing the basis for decision-making of plug remover. As we known, many factors such as permeability of reservoir rock, plugging degree, plug removal agent concentration and the injection parameters, all will influence the plug removal effect. In order to determine the influence of various factors and decrease the experimental workload, orthogonal experimental method was used to design the experiment scheme in this paper.

Experimental drugs and instruments. The experimental equipment: core displacement device under high temperature and high pressure, which produced by Nantong Huaxing Petroleum Instrument Limited Company.

Experimental materials: simulated formation water (prepared in laboratory according to chemical composition of Gaosheng Oilfield), crude oil from Gaosheng Oilfield(500 $\mathrm{mPa} \cdot \mathrm{s})$, the plug removal agent (sampled from well site), artificial cylindrical core(prepared by Northeast Petroleum University), $\mathrm{CaCl}_{2}(96.0 \%), \mathrm{Na}_{2} \mathrm{CO}_{3}(99.8 \%)$. The experimental temperature: $50{ }^{\circ} \mathrm{C}$.

\section{Experimental procedures.}

(1) Prepare 5\%, 6\%, 7\% plug removal agent solution.

(2) Dry the core and saturate it with simulated formation water, then saturate it with oil by displacing device and maturate it. Displace the core with the simulated formation water until the remaining oil saturation is $60 \%$ and measure the core permeability $K_{0}$ with water. 
(3) Inject 2PV calcium chloride solution into the cores by the injection rate of $0.5 \mathrm{~mL} / \mathrm{min}$. Then inject into 2PV sodium carbonate solution. After reacting a period of time, measure core permeability $K_{1}$ by water. If $\left(K_{0}-K_{1}\right) / K_{0}<0.5$ (The plugging degree is less than 0.5 ), alternating injection of calcium chloride and sodium carbonate solution will be continued until $\left(K_{0}-K_{1}\right) / K_{0}<0.5$ close to a predetermined plugging degree of $K_{\mathrm{k}}$.

(4) Inject predetermined PV of plug removal agent solution into the core by the injection rate of $0.5 \mathrm{~mL} / \mathrm{min}$. After $4 \mathrm{~h}$ still state, measure the core permeability $K_{2}$ with simulated formation water. Calculate plug removal rate $R_{\mathrm{pr}}$

$$
R_{\mathrm{pr}}=\frac{K_{2}-K_{1}}{K_{0}-K_{1}} \times 100 \%
$$

(5) Repeat the above steps according to the predetermined experimental plan successively.

Orthogonal experiment scheme and analysis of experimental results. According to the experimental procedures above, 9 core samples with different gas permeability $K_{\mathrm{g}}$ were selected, measuring plug degree $P_{\mathrm{d}}$, concentration of plug removal agent $C_{\mathrm{r}}$, injected volume $V_{\mathrm{j}}$, the core water permeability in the oil saturation of $60 \% K_{0}$, the core water permeability before and after plug removal $K_{1}$ and $K_{2}$ were measured, then $P_{\mathrm{rr}}$ was calculated (refer with Table 1, Fig.1 - Fig. 4).

Table 1. experimental and calculated data

\begin{tabular}{c|c|c|c|c|c|c|c|c}
\hline $\begin{array}{c}\text { Core } \\
\text { name }\end{array}$ & $\begin{array}{c}K_{\mathrm{g}} \\
\left(10^{-3} \mu \mathrm{m}^{2}\right)\end{array}$ & $\begin{array}{c}P_{\mathrm{d}} \\
(\%)\end{array}$ & $\begin{array}{c}C_{\mathrm{r}} \\
(\%)\end{array}$ & $\begin{array}{c}V_{\mathrm{j}} \\
(\mathrm{PV})\end{array}$ & $\begin{array}{c}K_{0} \\
\left(10^{-3} \mu \mathrm{m}^{2}\right)\end{array}$ & $\begin{array}{c}K_{1} \\
\left(10^{-3} \mu \mathrm{m}^{2}\right)\end{array}$ & $\begin{array}{c}K_{2} \\
\left(10^{-3} \mu \mathrm{m}^{2}\right)\end{array}$ & $\begin{array}{c}R_{\mathrm{pr}} \\
(\%)\end{array}$ \\
\hline GS-1 & 516 & 51.2 & 5 & 1 & 172.0 & 84.3 & 199.2 & 75.58 \\
\hline GS-2 & 507 & 72.1 & 6 & 2 & 169.0 & 47.3 & 184.2 & 75.66 \\
\hline GS-3 & 500 & 92.4 & 7 & 3 & 166.7 & 13.3 & 170.9 & 76.08 \\
\hline GS-4 & 2024 & 71.6 & 5 & 3 & 674.7 & 195.7 & 712.3 & 83.87 \\
\hline GS-5 & 2031 & 89.2 & 6 & 1 & 677.0 & 74.5 & 699.6 & 76.69 \\
\hline GS-6 & 2005 & 52.0 & 7 & 2 & 668.3 & 320.8 & 776.5 & 74.78 \\
\hline GS-7 & 3012 & 91.2 & 5 & 2 & 1004.0 & 90.4 & 1023.3 & 82.40 \\
\hline GS-8 & 2985 & 50.8 & 6 & 3 & 995.0 & 497.5 & 1091.4 & 83.77 \\
\hline GS-9 & 3084 & 68.3 & 7 & 1 & 1028.0 & 329.0 & 1139.7 & 74.65 \\
\hline average 1 & 75.77 & 78.04 & 80.62 & 75.64 & & & & \\
\hline average 2 & 78.45 & 78.06 & 78.71 & 77.61 & & & & \\
\hline average 3 & 80.27 & 78.39 & 75.17 & 81.24 & & & & \\
\hline $\begin{array}{c}\text { Level } \\
\text { difference }\end{array}$ & 4.50 & 0.48 & 5.45 & 5.60 & & & & \\
\hline $\begin{array}{c}\text { square } \\
\text { deviations }\end{array}$ & 47.90 & 0.24 & 31.22 & 45.82 & & & & \\
\hline
\end{tabular}

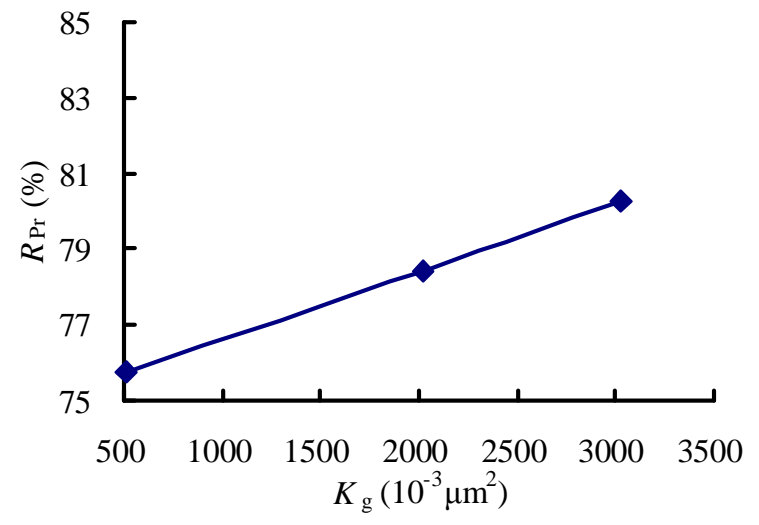

Figure 1. The effect of gas permeability on plug removal rate

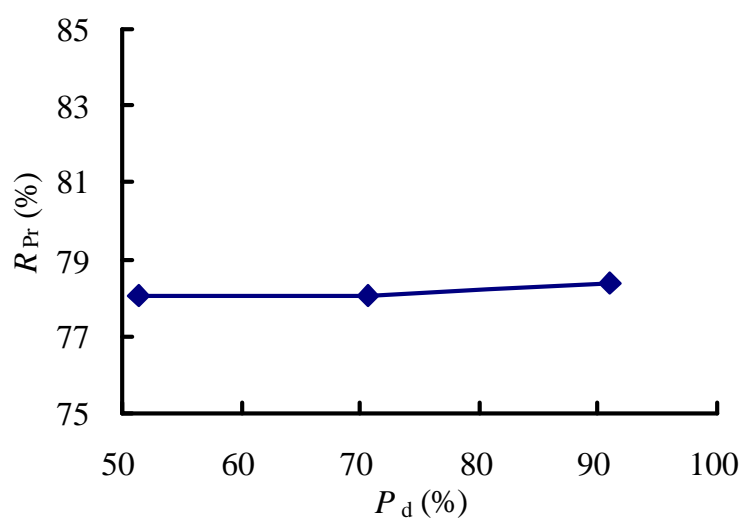

Figure 2. The effect of plugging degree on plug removal rate 


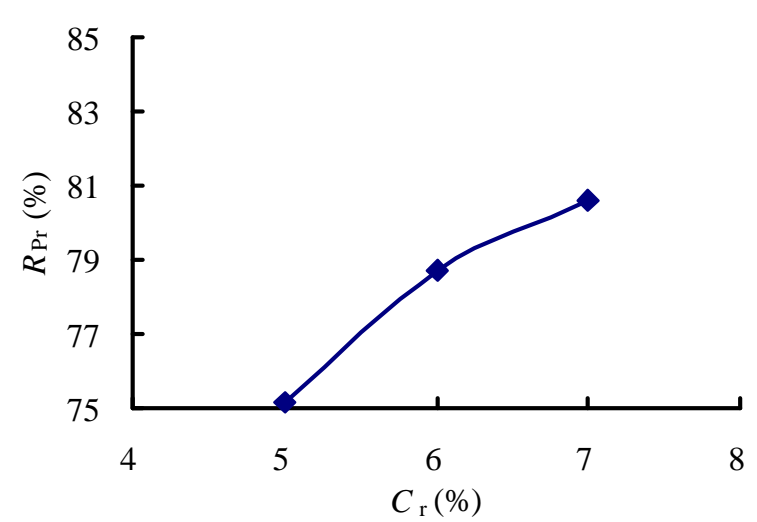

Figure 3. The effect of plug removal agent concentration on plug removal rate

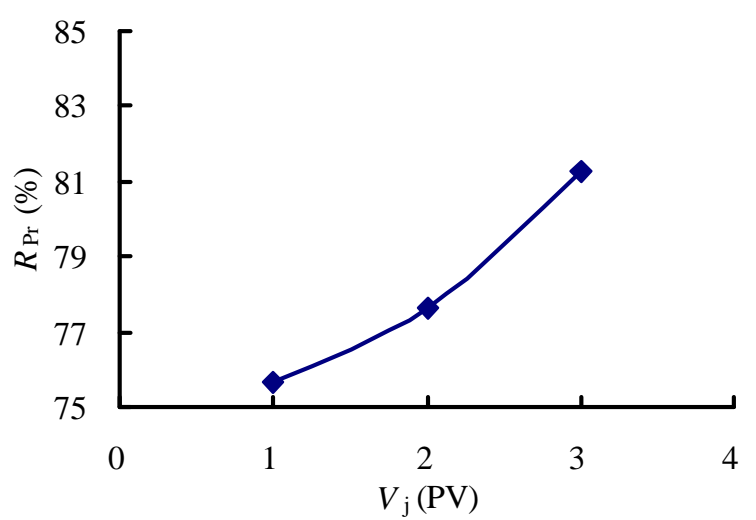

Figure 4. The effect of injection PV on plug removal rate

From Table1 and Figure 1 to Figure 4, we can see that, plug removal rate increased greatly with the increase of core permeability. With the increasing of the plug removal agent concentration and injection PV, plug removal rate increases obviously. With the change of plugging degree, the change of plug removal rate is not obvious. From the analysis of the orthogonal experiment results, we can see that the level difference of gas permeability is 4.50 , the level difference of plug remover concentration is 5.45, the level difference of the injected amount of plug remover is 5.60, and the level difference of the blockage degree is 0.48 . So the influence of permeability, the injected amount and the concentration of plug removal agent on plug removal effect is larger.

\section{Optimization of Injection Parameters}

The plugging degree is determined to be 0.7 . We have investigated the plug removal effect of $2000 \times 10^{-3} \mu \mathrm{m}^{2}$ permeability core under different injection quantity and different plug removal agent concentration. The experimental results are shown in Table 2,Table 3 and Figure 5, Figure 6.

Table 2. The influence of plug removal agent concentration (2.0 PV)

\begin{tabular}{c|c|c|c|c|c|c}
\hline Core name & $\begin{array}{c}K_{\mathrm{g}} \\
\left(10^{-3} \mu \mathrm{m}^{2}\right)\end{array}$ & $\begin{array}{c}C_{\mathrm{r}} \\
(\%)\end{array}$ & $\begin{array}{c}K_{0} \\
\left(10^{-3} \mu \mathrm{m}^{2}\right)\end{array}$ & $\begin{array}{c}K_{1} \\
\left(10^{-3} \mu \mathrm{m}^{2}\right)\end{array}$ & $\begin{array}{c}K_{2} \\
\left(10^{-3} \mu \mathrm{m}^{2}\right)\end{array}$ & $\begin{array}{c}R_{\mathrm{pr}} \\
(\%)\end{array}$ \\
\hline GS-10 & 2032 & 3 & 677.3 & 203.2 & 560.3 & 75.32 \\
\hline GS-11 & 1998 & 4 & 666.0 & 199.8 & 561.4 & 77.56 \\
\hline GS-12 & 1996 & 5 & 665.3 & 199.6 & 578.5 & 81.35 \\
\hline GS-13 & 2015 & 6 & 671.7 & 201.5 & 586.3 & 81.84 \\
\hline GS-14 & 2010 & 7 & 670.0 & 201.0 & 586.2 & 82.14 \\
\hline
\end{tabular}

Table 3. The influence of plug removal agent solution amount (concentration is $5 \%$ )

\begin{tabular}{c|c|c|c|c|c|c}
\hline Core name & $\begin{array}{c}K_{\mathrm{g}} \\
\left(10^{-3} \mu \mathrm{m}^{2}\right)\end{array}$ & $\begin{array}{c}V_{\mathrm{j}} \\
(\mathrm{PV})\end{array}$ & $\begin{array}{c}K_{0} \\
\left(10^{-3} \mu \mathrm{m}^{2}\right)\end{array}$ & $\begin{array}{c}K_{1} \\
\left(10^{-3} \mu \mathrm{m}^{2}\right)\end{array}$ & $\begin{array}{c}K_{2} \\
\left(10^{-3} \mu \mathrm{m}^{2}\right)\end{array}$ & $\begin{array}{c}R_{\mathrm{pr}} \\
(\%)\end{array}$ \\
\hline GS-15 & 2020 & 1.0 & 673.3 & 202.0 & 563.5 & 76.69 \\
\hline GS-16 & 2011 & 1.5 & 670.3 & 201.1 & 569.7 & 78.55 \\
\hline GS-17 & 1983 & 2.0 & 661.0 & 198.3 & 574.0 & 81.20 \\
\hline GS-18 & 1998 & 2.5 & 666.0 & 199.8 & 580.9 & 81.74 \\
\hline GS-19 & 2004 & 3.0 & 668.0 & 200.4 & 587.7 & 82.83 \\
\hline
\end{tabular}

From the Figure 5 and Figure 6 above, we know that increasing the concentration of lug removal agent an improve the plug removal rate when the lug removal agent injection amount is at the same value. hen the lug removal agent concentration is $5 \%$, he plug removal rate can reach more than $81 \%$. When the concentration of plug removal agent is increased further more, the plug removal 
rate will not increase significantly. For a certain permeability core, increasing plug removal agent injection amount can improve the plug removal rate when plug removal agent concentration is at same value for a certain permeability core. When 2.0 PV plug removal agent is injected into the core, plug removal rate reached more than $81 \%$. But when the amount of plug removal agent injected is increased further more, plug removal rate does not increased significantly. Therefore, for the artificial core with $2000 \times 10^{-3} \mu \mathrm{m}^{2}$ gas permeability, the best plug removal agent concentration is $5 \%$ and the best injection dosage is $2.0 \mathrm{PV}$.

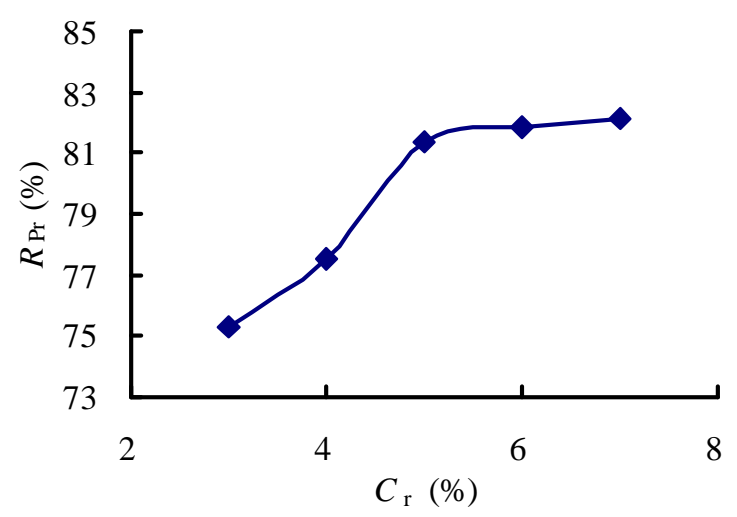

Figure 5. The influence of plug removal agent concentration on plug removal rate

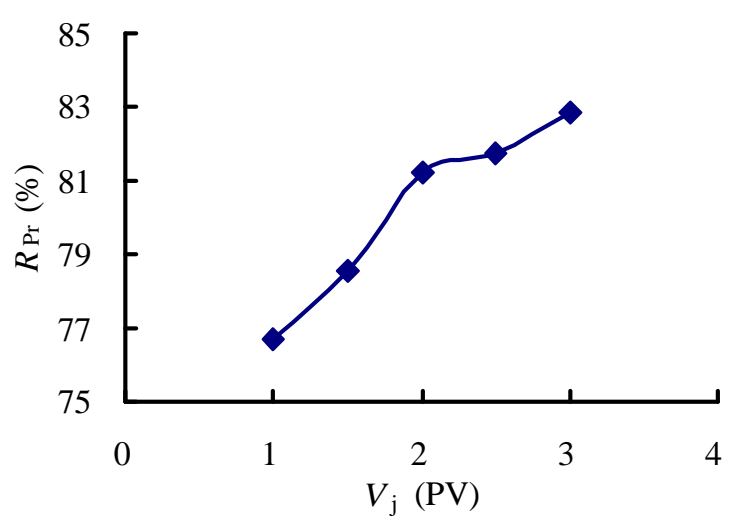

Figure 6. The influence of injected PV on plug removal rate

From the Figure 1 and Figure 2 above, we know that increasing the concentration of plug removal agent can improve the plug removal rate when the plug removal agent injection amount is at the same value. When the plug removal agent concentration is $5 \%$, the plug removal rate can reach more than $81 \%$. When the concentration of plug removal agent is increased further more, the plug removal rate will not increase significantly.

For a certain permeability core, increasing plug removal agent injection amount can improve the plug removal rate when plug removal agent concentration is at same value for a certain permeability core. When 2.0 PV plug removal agent is injected into the core, plug removal rate reached more than $81 \%$. But when the amount of plug removal agent injected is increased further more, plug removal rate does not increased significantly. Therefore, for the artificial core with $2000 \times 10^{-3} \mu \mathrm{m}^{2}$ gas permeability, the best plug removal agent concentration is $5 \%$ and the best dosage is $2.0 \mathrm{PV}$.

\section{Conclusions}

(1) The influence of permeability, the injected amount and the concentration of plug removal agent on improve the permeability is larger.

(2) Plug removal rate can be improved by adjusting injection amount and concentration of plug removal agent. When the plug removal agent concentration is $5 \%$, the plug removal rate can reach more than $81 \%$.

(3)The best dosage of plug removal agent solution is $2.0 \mathrm{PV}$ and the best injected concentration is $5 \%$ for the artificial core with $2000 \times 10^{-3} \mu \mathrm{m}^{2}$ gas permeability.

\section{References}

[1] Yufen Mei. The research and application of oxidant-retarded acid compound plug removal technology in Gaosheng oilfied, Technology Innovation and Application. 25(2013) 24-27.

[2] Jianmei Liang. The plug removal and stimulation technology research on water flooding well after polymer flooding. Inner Mongolia Petrochemical Industry, 14(2014) 112-115.

[3] Gang Hu. Integrated plug removal and stimulation technology of super heavy oil. Contemporary Chemical Industry, 7(2013) 64-67. 